\title{
Analysis of three level supply chain of inventory with deterioration for multi-items
}

\author{
Narayan Singh*, Bindu Vaish and S.R. Singh
}

Department of Mathematics D.N. (P.G) College, Meerut (U.P), India

\section{CH R O N I C L E}

\section{Article history:}

Received October 22013

Received in Revised Format

Mach 172014

Accepted March 282014

Available online

April 12014

Keywords:

Multi-item inventory

Deteriorating items

Three level supply chains \begin{abstract}
A B S T R A C T
The objective of this work is to generalize the three echelon supply chain model proposed by Jaber and Goyal (2008) [Jaber, M. Y., \& Goyal, S. K. (2008). Coordinating a three-level supply chain with multiple suppliers, a vendor and multiple buyers. International Journal Production Economics, 116, 95-103.] for multi-items where single item was considered in production and distribution. This paper develops the coordination amongst different parties in a three-echelon supply chain with a centralized decision process. Producer, suppliers and retailers are the parties of the supply chain where multiple suppliers deliver various types of raw materials to a producer; producer produces different types of items, multi-items, in different units of the factory and supplies the items to multiple retailers. Different deterioration rates for finished items and raw materials are also considered. The model developed of this paper guarantees that the local costs for the members either remain the same as before coordination, or decrease as a result of coordination. A numerical example along with graphical illustrations is considered and the sensitivity analysis is provided to test the feasibility of the proposed model.
\end{abstract}

(C) 2014 Growing Science Ltd. All rights reserved

\section{Introduction}

A supply chain normally consists of various facilities, where raw materials, intermediate products, or finished goods, which are purchased, produced, processed, stored or sold and they are inter-connected through transportation links, networks, along which the products flow. These facilities can be managed by one company and can be operated by vendors, customers, third-party providers, as divisions of other firms in which the company has business arrangements. To manage the effective and efficient flow of raw materials and products, coordination of activities is necessary among different players of the supply chain. Coordination schemes in supply chains are either centralized or decentralized decisionmaking processes. A centralized decision-making process assumes a unique decision-maker (a team) managing the whole supply chain with an objective to minimize (maximize) the total supply chain cost (profit); whereas in a decentralized decision-making process, multiple decision-makers with conflicting objectives are involved. This paper assumes a centralized decision-making process as a coordination mechanism in the supply chain model discussed herein (e.g., Munson \& Rosenblatt, 2001; Jaber et al., 2006).

* Corresponding author. Tel: +923009521379

E-mail: narayansingh1980@yahoo.co.in (N. Singh)

(C) 2014 Growing Science Ltd. All rights reserved.

doi: $10.5267 /$ j.jijiec.2014.4.001 
Clark and Scarf (1960) were the first to study the two-echelon inventory model. They proved the optimality of a base stock policy for the pure serial inventory system and developed an efficient decomposing method to compute the optimal base stock ordering policy. Integrating inventory decision models of parties in a supply chain is a natural way of achieving coordination (e.g., Goyal \& Gupta, 1989). Investigations reporting coordination in a three-level supply chain are few and far between in the literature. Coordinating orders in a two-level (vendor-buyer(s)) supply chain has been addressed by Hill (1997). Goyal and Gunasekaran (1995) observed an integrated production- inventory-marketing model to determine economic production quantity and economic order quantity for raw materials in a multi-echelon production system. Thomas and Grifin (1996) remarked that an efficient supply chain requires planning and coordination among the various channels. Goyal (2000) discussed the singlevendor single-buyer integrated production inventory model with a generalized policy.

The literature on multi-item dynamic inventory models is really sparse, since most of the classical studies are concerned with a single-item inventory model. We cite some of the most well-known works in order to give an idea on the wide range of optimal control applications in the multi-item inventoryproduction system. Ben-Daya and Raouf (1993) developed an approach for a more realistic and general Single Period Inventory Problem (SPIP), they considered a multi-item with budgetary and floor- or shelf- space constraints and assumed that, the demand of the items follows uniform probability distribution. In addition, they discussed a multi-item inventory model with stochastic demand subject to the restrictions on available space and budget. Lenard and Roy (1995) defined another approach to determine inventory policies based on the notion of efficient policy surface and extend this notion to multi-item inventory control by defining the concepts of family and aggregate item. Rosenblatt (1981) discussed multi-item inventory system with budgetary constraint comparison between the Lagrangian and the fixed cycle approach.

The area of supply chain management has gained significant amount of interest from researchers as well as practitioners in the industry. For a vertically integrated supply chain owned partially or jointly by the same company, such coordinated production- shipment policy provides valuable insights and optimal decisions, which lead to global optimization. On the other hand, when individual entities are owned separately, such policy may not benefit all parties equally as some may encounter an increase in their costs and hence become less eager to depart from their locally optimized policies. In such circumstances, sharing those benefits resulting from the coordinated approach becomes a major issue. By using effective incentive systems such as accounting methods, transfer pricing schemes, quantity discount, etc., the objective of each partner can be aligned to that of the supply chain as a whole (Ganeshan, 1999). Munson and Rosenblatt (2001) considered a single-product centralized three-level supply chain consisting of a single supplier, a single manufacturer, and a single retailer. In their model, Munson and Rosenblatt (2001) assumed that the manufacturer is the most influential channel player who would be able to obtain a quantity discount from the supplier without worsening the supplier's financial performance. The manufacturer may pass some, or all, of the monetary discount obtained from the supplier to the retailer to entice the retailer to order in larger lots than its economic order quantity (EOQ). They also suggested that the compensation paid to the retailer is the difference in holding and ordering costs between the retailer's old (no coordination) and new ordering (with coordination) policies. Viswanathan and Wang (2003) discussed a discount pricing decisions in distribution channels with price-sensitive demand. Jain and Singh (2011) developed an inflation implication on an inventory with expiration date, capital constraint and uncertain lead time in a multiechelon supply chain. Jaber and Goyal (2008) discussed coordination a three-level supply chain with multiple suppliers, a vendor and multiple buyers. Sadjadi et al (2012) considered a profit maximizing firm who wants to jointly determine the optimal lot-sizing, pricing, and marketing decisions along with manufacturing requirements in terms of flexibility and reliability of the process. Singh et al. (2012) studied a three echelon supply chain inventory model for deteriorating items with storage facility and lead time under inflation. Pal et al (2012) discussed a production inventory model for different types of items where multiple suppliers, a manufacturer and the multiple non-competing retailers were the members of the supply chain. In this model, each supplier supplies only one type of raw material to the 
manufacturer. The manufacturer produces a finished item by the combination of certain percentage of the various types of raw materials. The manufacturer produces also multi-items and delivers them according to the demand of the different retailers. Tsao and Sheen (2012) considered a multi-item supply chain with a credit period and weight freight cost discounts. Aliabadi et al. (2013) investigated an integrated multi-item supplier selection model. The mathematical model, which is a nonlinear binary programming was derived. Hanbali and Heijden (2013) analyzed the interval availability of a twoechelon, multi-item spare part inventory system. They considered a scenario inspired by a situation that they encountered at Thales Netherlands, a manufacturer of naval sensors and naval command and control systems. Chui et al. (2013) addressed the joint determination of a rotation cycle time and number of shipments for a multi-item EPQ model with random defective rate.

Jaber and Goyal (2008) in a novel work discussed the supply chain with multiple suppliers by investigating a problem where a manufacturer and multiple buyers for the production of single item are involved. We extend the paper this work for multi-items, production and supply, and consider the number of suppliers equal to the number of items required by the manufacture of the product to assemble one unit of the finished product. We consider a three-layer supply chain model involving multiple suppliers, a producer and multiple retailers as members of the chain. The multiple suppliers supply raw materials to a producer who produces multiple finished products, which are delivered to the multiple retailers and the retailer sale the items to the customers. This model have been accomplished with the different rate of deterioration i.e. a deterioration rate for raw material and another deterioration rate for finished items of retailers. The setup has been explored numerically as well, an optimal solution has been reached at and the sensitivity of that solution has also been checked with respect to various system parameters. The result shows that the model is not only economically feasible but also it provides stable results. A cost minimization model is derived along with an efficient solution algorithm that is based on the calculus approach.

\section{Assumptions and Notations}

In this study, we assume

\subsection{Assumptions}

1. Demand rate and production rate are deterministic and constant.

2. Production rate is highly greater than any demand d, i.e. $P>d$.

3. One product requires $m$ items.

4. Shortage is not allowed.

5. Lead time is zero at each level of the supply chain.

6. Time horizon is infinite.

7. Multi-items are considered.

8. A constant fraction of the on hand inventory deteriorates and no replacement of

Deteriorated items are allowed.

9. Multiple suppliers, single producer and multiple retailers are considered.

10. Single producer produces multi-items of different kinds.

11. The study considered supplier producer and retailer co-operation.

\subsection{Notations}

The input parameters and decision variables for retailers, producer and suppliers are denoted by the subscripts $r, p$ and $s$, respectively.

$n \quad$ Number of items, where $i=1,2,3, \ldots \ldots \mathrm{n}$

$\mathrm{m} \quad$ Number of supplier and each supplier supply $\mathrm{n}$ different kind of items to the producer for producing $\mathrm{n}$ different items or number of units required in one unit of the finished product. 
$\mathrm{k} \quad$ Number of retailers

$l \quad$ Number of deliveries from producer to the retailer during total cycle time

$d_{i} \quad$ Annual demand rate of $i^{\text {th }}$ item (units/year)

$P_{i} \quad$ Production rate of $i^{\text {th }}$ item, where $i=1,2,3, \ldots \ldots \mathrm{n}$

$I_{S}(t) \quad$ Inventory level of supplier

$I_{p}(t) \quad$ Inventory level of producer

$I_{r}(t) \quad$ Inventory level of retailer

$\theta_{1 i} \quad$ Inventory deterioration rate for supplier

$\theta_{2 i} \quad$ Inventory deterioration rate for producer

$\theta_{3 i} \quad$ Inventory deterioration rate for retailer

$A_{r \alpha} \quad$ Ordering cost per cycle for $\alpha^{\text {th }}$ retailer where $\alpha=1,2,3, \ldots . . k$

$h_{r \alpha} \quad$ Holding cost of $\alpha^{\text {th }}$ retailer per unit per year

$A_{s j} \quad$ Order cost for supplier $\mathrm{j}$ where $j=1,2,3, \ldots . . \mathrm{m}$

$A_{p} \quad$ Fixed order/setup cost per cycle for producer

$h_{p} \quad$ Holding cost per unit of a finished product per year

$h_{s j} \quad$ Holding cost per unit per unit time for $j^{\text {th }}$ supplier

$c_{0} \quad$ Fixed cost per unit of the product

$c_{p i} \quad$ Producer's finished goods per unit cost

$c_{r \alpha} \quad$ Retailer's finished goods per unit cost

$c_{s j} \quad$ Supplier's raw material per unit cost

$Q_{s} \quad$ One kind of raw material's order quantity for one supplier

$Q_{p} \quad$ Producer's finished goods production quantity per production

$Q_{r} \quad$ One retailer's received quantity of one kind per delivery from producer

$M I_{p} \quad$ The maximum inventory level of producer

$M I_{r} \quad$ Inventory lot size of all k retailers in one delivery of $i^{\text {th }}$ item

$T_{1} \quad$ The production period

$T_{2} \quad$ The non-production period

$T_{3} \quad$ The period that a retailer is not out of stock

$T \quad$ Cycle time

$T C S \quad$ Supplier's total cost per unit time

$T C P$ Producer's total cost per unit time

$T C R \quad$ Retailer's total cost per unit time

$T C$ The total system cost

\section{Mathematical Model}

The following scope applies to the study. Suppliers procure raw materials from outside suppliers and deliver the fixed quantities to the producer's warehouse at a fixed time interval. The producer withdraws raw materials from the warehouse and produces finished goods. The fixed quantities finished goods is delivered to retailers at a fixed time interval. This study develops an integrated inventory model for deteriorating multi-items under a multi-echelon supply chain system and is shown in Fig. 1. A mathematical model with integrating multiple suppliers, single producer and multiple retailers is derived to obtain the optimal number of deliveries, production time/non-production time and 
order lot size, when the joint total cost of the supplier, the producer and the retailer under centralization is minimized.

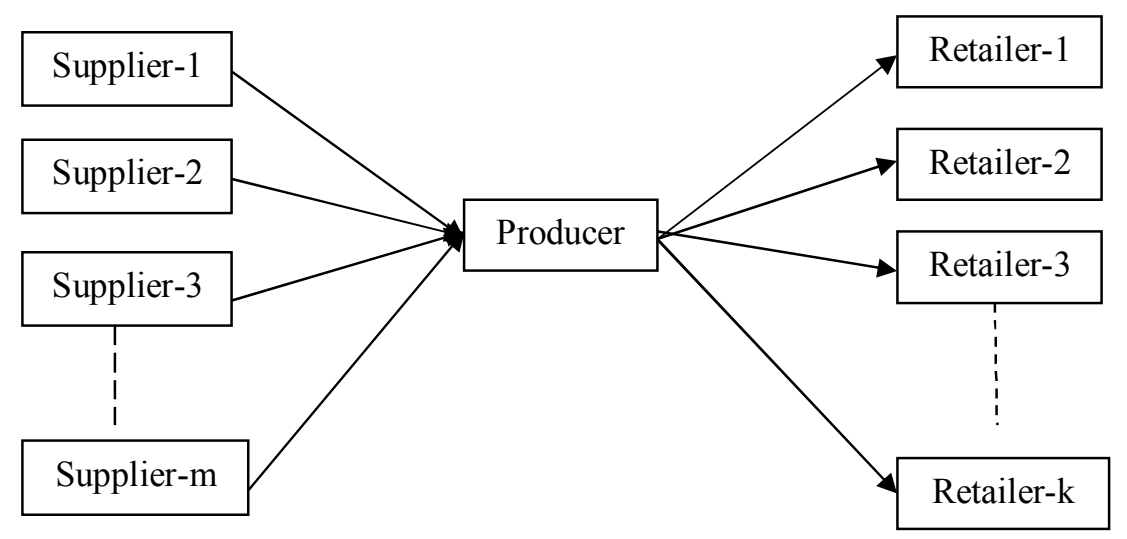

Fig.1. A three-echelon supply chain system

\subsection{Supplier's Inventory Model}

The raw materials Inventory System is shown in Fig 2(a). A supplier procures the raw materials and delivers the fixed quantities $Q_{s}$ to the producer's warehouse at a fixed-time interval. The producer withdraws raw materials from the warehouse. During the time period $T_{1}$, the inventory level decreases due to both producers demand and deterioration. The supplier's inventory system can be represented by the following first order linear differential equation;

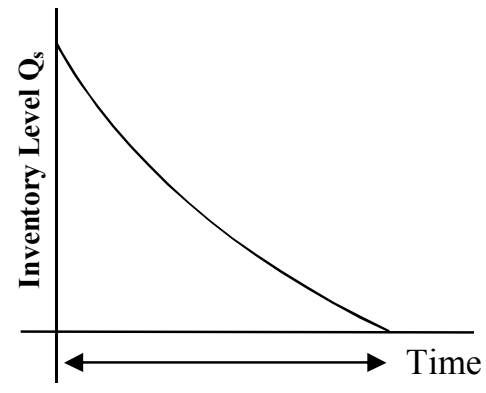

$\mathrm{T}_{1} \quad$ Fig. 2. (a)

$\frac{d I_{s i}\left(t_{1}\right)}{d t_{1}}=-\sum_{j=1}^{m} P_{i j}-\theta_{1 i} I_{s i}\left(t_{1}\right) \quad 0 \leq t_{1} \leq T_{1}$ and $i=1,2,3, \ldots n$

Using the boundary condition, $I_{s i}\left(T_{1}\right)=0$, the differential equation can be solved as follows,

$I_{s i}\left(t_{1}\right)=\sum_{j=1}^{m} P_{i j} \frac{\left\{e^{\theta_{1 i}\left(T_{1}-t_{1}\right)}-1\right\}}{\theta_{1 i}} \quad$ where $0 \leq t_{1} \leq T_{1}$

Based on Fig. 2 (a) and $I_{s i}(0)=Q_{s}$, the maximum inventory level of raw material, i.e., the order quantity per order from outside suppliers is as follows,

$Q_{s}=\sum_{j=1}^{m} P_{i j} \frac{\left\{e^{\theta_{1 i} T_{1}}-1\right\}}{\theta_{1 i}} \approx \sum_{j=1}^{m} P_{i j}\left(T_{1}+\frac{\theta_{1 i} T_{1}^{2}}{2}\right)$

For one supplier inventory level at any time $t_{1}$ is

$I_{s i}\left(t_{1}\right)=P_{i 1} \frac{\left\{e^{\theta_{1 i}\left(T_{1}-t_{1}\right)}-1\right\}}{\theta_{1 i}}, Q_{s}=I_{s i}(0)=P_{i 1}\left(T_{1}+\frac{\theta_{1 i} T_{1}^{2}}{2}\right)$

1. There is an initial replenishment ordering cost at the start of the cycle is 
$O C_{s}=\sum_{j=1}^{m} A_{s i j}$

2. Inventory is carried during the time period $T_{1}$. The holding cost for supplier is

$$
\begin{aligned}
& H C_{S}=\sum_{j=1}^{m} h_{s i j} \int_{0}^{T_{1}} I_{s i}\left(t_{1}\right) d t_{1}=\sum_{j=1}^{m} \frac{h_{s i j} P_{i j}}{\theta_{1 i}} \int_{0}^{T_{1}}\left\{e^{\theta_{1 i}\left(T_{1}-t_{1}\right)}-1\right\} d t_{1} \\
& H C_{S} \approx \sum_{j=1}^{m} h_{s i j} P_{i j}\left(\frac{T_{1}^{2}}{2}+\frac{\theta_{1 i} T_{1}^{3}}{6}\right)
\end{aligned}
$$

3. The item cost includes the loss due to deterioration as well as the cost of the item sold.

$$
I T_{s}=c_{s i j} Q_{s} \approx \sum_{j=1}^{m} c_{s i j} P_{i 1}\left(T_{1}+\frac{\theta_{1 i} T_{1}^{2}}{2}\right)
$$

The total cost during the cycle is the sum of the ordering cost $\left(O C_{s}\right)$, the holding cost $\left(H C_{S}\right)$ and the item cost $\left(I T_{s}\right)$ for all $\mathrm{m}$ suppliers per unit time is as follows,

$$
\begin{aligned}
& T C S=\frac{O C_{s}+H C_{S}+I T_{s}}{T} \\
& T C S \approx \frac{1}{T} \sum_{i=1}^{n} \sum_{j=1}^{m}\left[A_{s i j}+h_{s i j} P_{i j}\left(\frac{T_{1}^{2}}{2}+\frac{\theta_{1 i} T_{1}^{3}}{6}\right)+c_{s i j} P_{i j}\left(T_{1}+\frac{\theta_{1 i} T_{1}^{2}}{2}\right)\right]
\end{aligned}
$$

\subsection{Producer's Inventory Model}

The manufactures inventory system in Fig. 2(b) can be divided into two independent phases depicted by $T_{1}$ and $T_{2}$. This methodology reduces the complexity of our problems derivation on and analysis. Each phase has its own time unit, $t_{i}$ which starts from the beginning of the phase $T_{i}$. During time period $T_{1}$ there is an inventory buildup and hence deterioration becomes effective. At $t_{1}=T_{1}$, the production stops and the inventory level increase to its maximum level $M I_{p}$. There is no production during period $T_{2}$, the inventory level decrease due to demand and deterioration. The Inventory level becomes zero at $t_{2}=T_{2}$.

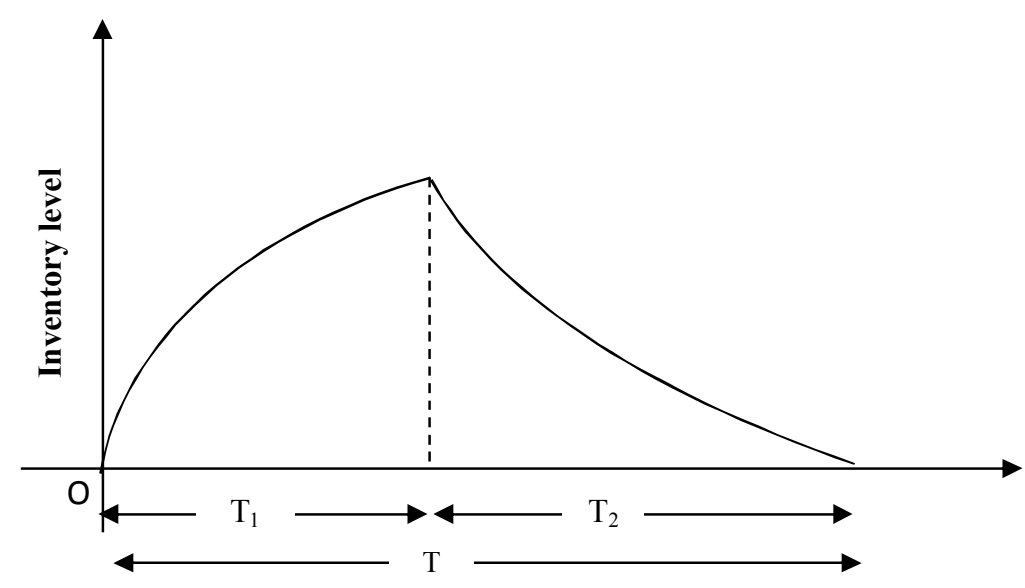

Fig. 2 (b)

The instantaneous state of inventory for the $i^{t h}$ item $(1 \leq i \leq n)$ over the cycle time $T_{i}$ is given by the following first order linear differential equation; 
$\frac{d I_{p_{1} i}\left(t_{1}\right)}{d t_{1}}=P_{i}-\sum_{\alpha=1}^{k} d_{i \alpha}-\theta_{2 i} I_{p_{1} i}\left(t_{1}\right) 0 \leq t_{1} \leq T_{1} \quad i=1,2,3, \ldots n$

$\frac{d I_{p_{2} i}\left(t_{2}\right)}{d t_{2}}=-\sum_{\alpha=1}^{k} d_{i \alpha}-\theta_{2 i} I_{p_{2} i}\left(t_{2}\right) \quad 0 \leq t_{2} \leq T_{2}$

The above differential equations are solved by using the boundary conditions,

$$
\begin{gathered}
I_{p_{1} i}(0)=0, I_{p_{2} i}\left(T_{2}\right)=0, \text { One has; } \\
I_{p_{1} i}\left(t_{1}\right)=\left(P_{i}-\sum_{\alpha=1}^{k} d_{i \alpha}\right) \cdot\left(\frac{1-e^{-\theta_{2 i} t_{1}}}{\theta_{2 i}}\right) \quad 0 \leq t_{1} \leq T_{1} \\
I_{p_{2} i}\left(t_{2}\right)=\sum_{\alpha=1}^{k} d_{i \alpha} \cdot\left(\frac{e^{\theta_{2 i}\left(T_{2}-t_{2}\right)}-1}{\theta_{2 i}}\right) \quad 0 \leq t_{2} \leq T_{2}
\end{gathered}
$$

Since $I_{p_{2 i}}(0)=M I_{p}$ the producer's maximum inventory level is

$$
M I_{p}=\sum_{\alpha=1}^{k} d_{i \alpha} \cdot\left(\frac{e^{\theta_{2 i} T_{2}}-1}{\theta_{2 i}}\right) \approx \sum_{\alpha=1}^{k} d_{i \alpha}\left(T_{2}+\frac{\theta_{2 i} T_{2}^{2}}{2}\right)
$$

The production quantity of the item is $Q_{p i}=P_{i} \cdot T_{1}$

1. At the of the cycle, the has an initial production setup cost and it is $S_{p}=A_{p i}$

2. Inventory is carried during $T_{1}$ and $T_{2}$ periods. If this system does not consider the retailer, all of holding cost belongs to producer. They are the first two terms of Eq. (15). If this system considers the retailer, the holding costs of the items delivered to the retailer belong to the retailer and it should be subtracted from producer, which is the last term in Eq. (15).

The holding cost for producer is

$$
\begin{aligned}
& H C_{p}=h_{p i}\left[\int_{0}^{T_{1}} I_{p_{1} i}\left(t_{1}\right) d t_{1}+\int_{0}^{T_{2}} I_{p_{2} i}\left(t_{2}\right) d t_{2}-l \int_{0}^{T_{3}} I_{r i}\left(t_{3}\right) d t_{3}\right] \\
& H C_{p}=h_{p i}\left[\int_{0}^{T_{1}}\left(P_{i}-\sum_{\alpha=1}^{k} d_{i \alpha}\right) \cdot\left(\frac{1-e^{-\theta_{2 i} t_{1}}}{\theta_{2 i}}\right) d t_{1}+\int_{0}^{T_{2}} \sum_{\alpha=1}^{k} d_{i \alpha} \cdot\left(\frac{e^{\theta_{2 i}\left(T_{2}-t_{2}\right)}-1}{\theta_{2 i}}\right) d t_{2}-l \int_{0}^{T_{3}} \sum_{\alpha=1}^{k} d_{i \alpha} \cdot\left(\frac{e^{\theta_{3 i}\left(T_{3}-t_{3}\right)}-1}{\theta_{3 i}}\right) d t_{3}\right] \\
& H C_{p} \approx h_{p i}\left[\left(P_{i}-\sum_{\alpha=1}^{k} d_{i \alpha}\right) \cdot\left(\frac{T_{1}^{2}}{2}-\frac{\theta_{2 i} T_{1}^{3}}{6}\right)+\sum_{\alpha=1}^{k} d_{i \alpha} \cdot\left(\frac{T_{2}^{2}}{2}+\frac{\theta_{2 i} T_{2}^{3}}{6}\right)-l \sum_{\alpha=1}^{k} d_{i \alpha} \cdot\left(\frac{T_{3}^{2}}{2}+\frac{\theta_{3 i} T_{3}^{3}}{6}\right)\right] \\
& H C_{p} \approx h_{p i}\left[P_{i \cdot} \cdot\left(\frac{T_{1}^{2}}{2}-\frac{\theta_{2 i} T_{1}^{3}}{6}\right)-\sum_{\alpha=1}^{k} d_{i \alpha} \cdot\left\{\frac{1}{2}\left(T_{1}^{2}-T_{2}^{2}+l T_{3}^{2}\right)-\frac{1}{6}\left(\theta_{2 i} T_{1}^{3}+\theta_{2 i} T_{2}^{3}-l \theta_{3 i} T_{3}^{3}\right)\right\}\right]
\end{aligned}
$$

3. Annual deterioration cost for producer is as follows,

$$
D C_{p}=c_{p i}\left(P_{i} \cdot T_{1}-l \cdot M I_{r i}\right) \approx c_{p i}\left[P_{i} \cdot T-l \sum_{\alpha=1}^{k} d_{i \alpha}\left(T_{3}+\frac{\theta_{3 i} T_{3}^{2}}{2}\right)\right]
$$

The total cost during the cycle is the sum of the setup cost $\left(S_{p}\right)$, the holding cost $\left(H C_{p}\right)$ and the deterioration cost $\left(D C_{p}\right)$ for producer per unit time is 


$$
\begin{aligned}
& T C P=\frac{S_{p}+H C_{p}+D C_{p}}{T} \\
& T C P \approx \frac{1}{T}\left[A_{p i}+h_{p i}\left\{P_{i} \cdot\left(\frac{T_{1}^{2}}{2}-\frac{\theta_{2 i} T_{1}^{3}}{6}\right)-\sum_{\alpha=1}^{k} d_{i \alpha} \cdot\left\{\frac{1}{2}\left(T_{1}^{2}-T_{2}^{2}+l T_{3}^{2}\right)-\frac{1}{6}\left(\theta_{2 i} T_{1}^{3}+\theta_{2 i} T_{2}^{3}-l \theta_{3 i} T_{3}^{3}\right)\right\}\right\}\right. \\
&\left.+c_{p i} \cdot\left\{P_{i} \cdot T-l \sum_{\alpha=1}^{k} d_{i \alpha}\left(T_{3}+\frac{\theta_{3 i} T_{3}^{2}}{2}\right)\right\}\right]
\end{aligned}
$$

For the production of $\mathrm{n}$ different kind of items

$$
\begin{aligned}
& T C P \approx \frac{1}{T} \sum_{i=1}^{n}\left[A_{p i}+c_{p i} \cdot\left\{P_{i} \cdot T-l \sum_{\alpha=1}^{k} d_{i \alpha}\left(T_{3}+\frac{\theta_{3 i} T_{3}^{2}}{2}\right)\right\}\right. \\
& \left.+h_{p i}\left\{P_{i} \cdot\left(\frac{T_{1}^{2}}{2}-\frac{\theta_{2 i} T_{1}^{3}}{6}\right)-\sum_{\alpha=1}^{k} d_{i \alpha} \cdot\left\{\frac{1}{2}\left(T_{1}^{2}-T_{2}^{2}+l T_{3}^{2}\right)-\frac{1}{6}\left(\theta_{2 i} T_{1}^{3}+\theta_{2 i} T_{2}^{3}-l \theta_{3 i} T_{3}^{3}\right)\right\}\right\}\right]
\end{aligned}
$$

\subsection{Retailer's Inventory Model}

A realization of the inventory level in the system is given in Fig. 2 (c). The depletion of the inventory level during $\left[0, T_{3}\right]$ is due to the joint effect of demand and deterioration. $M I_{r}$ is the lot size of one delivery for all $\mathrm{k}$ retailers of one kind of finished goods. Hence the differential equation, which describes the variation of inventory level $I_{r i}(t)$ with respect to time $t$ is as follows,

$\frac{d I_{r i}\left(t_{3}\right)}{d t_{3}}=-\sum_{\alpha=1}^{k} d_{i j}-\theta_{3 i} I_{r i}\left(t_{3}\right) \quad 0 \leq t_{3} \leq T_{3}$

with boundary condition $I_{r i}(0)=M I_{r i}$ or $I_{r i}\left(T_{3}\right)=0$

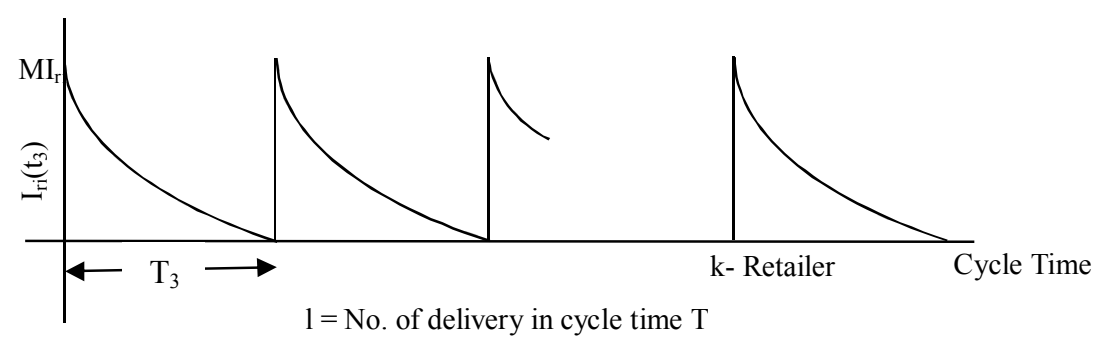

Fig. 2 (c)

The solution of the equation is as follows,

$I_{r i}\left(t_{3}\right)=\sum_{\alpha=1}^{k} d_{i \alpha} \cdot\left(\frac{e^{\theta_{3 i}\left(T_{3}-t_{3}\right)}-1}{\theta_{3 i}}\right) \quad 0 \leq t_{3} \leq T_{3}$

From the Fig. 2 (c) and $I_{r i}(0)=M I_{r i}$, the retailer's maximum inventory level is

$$
M I_{r i} \approx \sum_{\alpha=1}^{k} d_{i \alpha}\left(T_{3}+\frac{\theta_{3 i} T_{3}^{2}}{2}\right), Q_{r} \approx d\left(T_{3}+\frac{\theta_{3} T_{3}^{2}}{2}\right)
$$

1. The ordering cost is

$$
O C_{r}=\sum_{\alpha=1}^{k} A_{r i \alpha}
$$

2. Inventory carried during the period $T_{3}$. The holding cost for retailers is 
$H C_{r}=\sum_{\alpha=1}^{k} h_{r i \alpha} \cdot \int_{0}^{T_{3}} I_{r i}\left(t_{3}\right) d t_{3} \quad 0 \leq t_{3} \leq T_{3}$

$H C_{r}=\sum_{\alpha=1}^{k} h_{r i \alpha} \cdot \int_{0}^{T_{3}} \sum_{\alpha=1}^{k} d_{i \alpha} \cdot\left(\frac{e^{\theta_{3 i}\left(T_{3}-t_{3}\right)}-1}{\theta_{3 i}}\right) d t_{3} \approx \sum_{\alpha=1}^{k} h_{r i \alpha} d_{i \alpha}\left(\frac{T_{3}^{2}}{2}+\frac{\theta_{3 i} T_{3}^{3}}{6}\right)$

3. The item cost includes loss due to deterioration as well as the cost of item is

$$
I T_{r} \approx \sum_{\alpha=1}^{k} c_{r i \alpha} \cdot d_{i \alpha}\left(T_{3}+\frac{\theta_{3 i} T_{3}^{2}}{2}\right)
$$

The total cost during the cycle is the sum of the ordering cost $\left(O C_{r}\right)$, the holding cost $\left(H C_{r}\right)$ and the item cost $\left(I T_{r}\right)$ for producer per unit time is

$$
\begin{aligned}
T C R & =l \cdot \frac{O C_{r}+H D_{r}+I T_{r}}{T} \\
T C R & \approx \frac{l}{T}\left[\sum_{\alpha=1}^{k} A_{r i \alpha}+\sum_{\alpha=1}^{k} h_{r i \alpha} d_{i \alpha}\left(\frac{T_{3}^{2}}{2}+\frac{\theta_{3 i} T_{3}^{3}}{6}\right)+\sum_{\alpha=1}^{k} c_{r i \alpha} \cdot d_{i \alpha}\left(T_{3}+\frac{\theta_{3 i} T_{3}^{2}}{2}\right)\right] \\
& \approx \frac{l}{T} \sum_{\alpha=1}^{k}\left[A_{r i \alpha}+h_{r i \alpha} d_{i \alpha}\left(\frac{T_{3}^{2}}{2}+\frac{\theta_{3 i} T_{3}^{3}}{6}\right)+c_{r i \alpha} \cdot d_{i \alpha}\left(T_{3}+\frac{\theta_{3 i} T_{3}^{2}}{2}\right)\right] \quad \text { Where } T_{3}=\frac{T}{l}
\end{aligned}
$$

For $\mathrm{n}$ different items

$$
T C R \approx \frac{l}{T} \sum_{i=1}^{n} \sum_{\alpha=1}^{k}\left[A_{r i \alpha}+h_{r i \alpha} d_{i \alpha}\left(\frac{T_{3}^{2}}{2}+\frac{\theta_{3 i} T_{3}^{3}}{6}\right)+c_{r i \alpha} \cdot d_{i \alpha}\left(T_{3}+\frac{\theta_{3 i} T_{3}^{2}}{2}\right)\right]
$$

The relation between the period $T_{1}$ and $T_{2}$ can be computed by the Eq. (11) and Eq. (12). In order to solve the objective function, represent $T_{1}$ by $T_{2}$. From $I_{p_{1 i}}\left(T_{1}\right)=I_{p_{2 i}}(0)$, one has

$$
\left(P_{i}-\sum_{\alpha=1}^{k} d_{i \alpha}\right) \cdot\left(\frac{1-e^{-\theta_{2 i} T_{1}}}{\theta_{2 i}}\right)=\sum_{\alpha=1}^{k} d_{i \alpha} \cdot\left(\frac{e^{\theta_{2 i} T_{2}}-1}{\theta_{2 i}}\right)
$$

Neglecting second and higher degree term, from Eq. (26) and $T_{1}+T_{2}=T$ we get

$$
T_{1} \approx \frac{\sum_{\alpha=1}^{k} d_{i \alpha}}{P_{i}} . T, \quad T_{2} \approx \frac{\left(P_{i}-\sum_{\alpha=1}^{k} d_{i \alpha}\right)}{P_{i}} . T
$$

The study develops an integrated three echelon supply for multi-items under different rates of deterioration separately. For small rates $\theta_{1 i}, \theta_{2 i}$ and $\theta_{3 i}\left(\theta_{1 i}, \theta_{2 i}, \theta_{3 i} \leq 1\right)$, an approximate model with multiple supplier, single producer and multiple retailers with centralized decision policy is developed to derive the optimal production policy and lot size. The annual supply chain cost is determined by summing TCS, TCP and TCR. Since $T_{3}=T / l$ and $T_{1}+T_{2}=T$, the problem can be stated as an optimization problem and it can be formulated as

Minimize $T C(l, T)=T C S+T C P+T C R$

Subject to; $l \geq 1,0 \leq T$ 


\section{Analysis and solution procedure}

The objective of this study is to minimize the annual integrated system cost TC defined in Eq. (28). The following results are obtained.

\subsection{The convexity of the functions $T C(T)$}

For convenience, we treat the convexity property of function $\mathrm{TC}(\mathrm{T})$ defined on $\mathrm{T}>0$. At a particular value of $l$, Eq. (28) yields

$$
\begin{aligned}
& T C=\Delta_{1} T^{2}+\Delta_{2} T+\frac{1}{T} \Delta_{3}+\Delta_{4} \\
& T C^{!}=2 \Delta_{1} T+\Delta_{2}-\frac{1}{T^{2}} \Delta_{3} \\
& T C^{! !}=2 \Delta_{1}+\frac{2}{T^{3}} \Delta_{3}>0
\end{aligned}
$$

where

$$
\begin{aligned}
& \Delta_{1}=\sum_{i=1}^{n} \sum_{j=1}^{m} \sum_{\alpha=1}^{k}\left[\left\{h_{s i j} P_{i j} \theta_{1 i}+h_{p i}\left(P_{i}-d_{i \alpha}\right) \theta_{2 i}\right\} \frac{d_{i \alpha}^{3}}{6 P_{i}^{3}}+h_{p i} d_{i \alpha} \theta_{2 i} \frac{\left(P_{i}-d_{i \alpha}\right)^{3}}{6 P_{i}^{3}}+\frac{1}{6 l^{2}}\left(h_{r i \alpha}-h_{p i}\right) d_{i \alpha} \theta_{3 i}\right] \\
& \Delta_{2}=\sum_{i=1}^{n} \sum_{j=1}^{m} \sum_{\alpha=1}^{k}\left[\begin{array}{l}
\left\{\left(h_{s i j}+c_{s i j} \theta_{1 i}\right) P_{i j}+h_{p i}\left(P_{i}-d_{i \alpha}\right)\right\} \frac{d_{i \alpha}^{2}}{2 P_{i}^{2}}+h_{p i} d_{i \alpha} \frac{\left(P_{i}-d_{i \alpha}\right)^{2}}{2 P_{i}^{2}} \\
+\frac{1}{2 l}\left(h_{r i \alpha}-h_{p i}\right) d_{i \alpha}+\left(c_{r i \alpha}-P_{i}\right) d_{i \alpha} \theta_{3 i}
\end{array}\right]
\end{aligned}
$$$$
\Delta_{3}=\sum_{i=1}^{n} \sum_{j=1}^{m} \sum_{\alpha=1}^{k}\left[A_{s i j}+A_{p i}+l A_{r i \alpha}\right]
$$

and

$$
\Delta_{4}=\sum_{i=1}^{n} \sum_{j=1}^{m} \sum_{\alpha=1}^{k}\left[\left(\frac{c_{s i j} P_{i j}}{P_{i}}-c_{p i}+c_{r i \alpha}\right) d_{i \alpha}+c_{p i} P_{i}\right]
$$

Eq. (30) and Eq. (31) show that the following results hold true

Lemma 1. The function TC(T) is convex on T $>0$ if $\Delta_{1}, \Delta_{3}>0$ $P_{i}>d_{i \alpha}$ and $h_{r i \alpha}>h_{p i}$ this implies $P_{i}-d_{i \alpha}>0$ and $h_{r i \alpha}-h_{p i}>0$ (because of $\mathrm{h}_{\text {ri }}>\mathrm{h}_{\mathrm{pi}}$ )Therefore $\Delta_{1}>0$, $\Delta_{3}$ is the sum of all positive terms, that is, $\Delta_{3}>0$ By letting $T C^{\prime}=0$ and solving the eq. (30), we obtain

$$
\begin{aligned}
& T^{*}=\frac{\Delta_{2}^{2}}{6 \Delta_{1}\left(-\Delta_{2}^{3}+54 \Delta_{1}^{2} \Delta_{3}+6 \sqrt{3} \sqrt{-\Delta_{1}^{2} \Delta_{2}^{3} \Delta_{3}+27 \Delta_{1}^{4} \Delta_{3}^{2}}\right)^{1 / 3}} \\
& +\frac{\left(-\Delta_{2}^{3}+54 \Delta_{1}^{2} \Delta_{3}+6 \sqrt{3} \sqrt{-\Delta_{1}^{2} \Delta_{2}^{3} \Delta_{3}+27 \Delta_{1}^{4} \Delta_{3}^{2}}\right)^{1 / 3}}{6 G_{1}}-\frac{\Delta_{2}}{6 \Delta_{1}}
\end{aligned}
$$

Also if $\mathrm{T}^{*}$ exists then we find

$$
T C=\left\{\begin{array}{cc}
<0 & 0<T<T^{*} \\
=0 & T=T^{*} \\
>0 & T>T^{*}
\end{array}\right.
$$


Therefore it follows that the function TC is decreasing on $\left(0 \mathrm{~T}^{*}\right]$ and increasing on $\left[\mathrm{T}^{*} \infty\right)$.

\subsection{Solution procedure}

Require: Delivery per order $l$ where $l \in I^{+}$.

Ensure: minimum value $T C\left(l^{*}, T^{*}\right)$ of $T C(l, T)$ given in Eq. (28).

begin

Choose $l$ such that $l \geq 1$;

$$
\operatorname{TC}\left(l^{*}, T^{*}\right)=100^{100} ; \quad / / \text { initially we have taken a very large quantity }
$$

\section{Repeat}

$$
\begin{aligned}
& \text { find } \frac{\partial}{\partial T} T C(l, T) \\
& \begin{aligned}
& \text { put } \frac{\partial}{\partial T} T C(l, T) \text {; } 0 \text { and find all the values of } T ; / / \text { let } T_{1}, T_{2} \ldots \ldots . . T_{n} \text { are all such values of } T \\
& \text { for }(i=1 \text { to } n) \text { do } \\
& \text { if }\left(\frac{\partial^{2}}{\partial T^{2}}\left(T C\left(l, T_{i}\right)\right) \geq 0\right) \text { then } \\
& \text { calculate } T C\left(l, T_{i}\right) ; \\
& \quad \text { if }\left(T C\left(l, T_{i}\right) \leq T C\left(l^{*}, T_{i}^{*}\right)\right) \\
& \quad T C\left(l^{*}, T_{i}^{*}\right)=T C\left(l, T_{i}\right)
\end{aligned}
\end{aligned}
$$

\section{end if}

\section{end if}

\section{end for}

until (minimum value $T C\left(l^{*}, T^{*}\right)$ of $T C(l, T)$ is found for all possible values of $l$ )

derive the $T_{1}^{*}, T_{2}^{*} \ldots \ldots .$. and ....;

end

\section{Numerical Example}

Consider a three-echelon supply chain with three retailers $(\alpha=1,2,3)$, a producer and two suppliers $(j=1,2)$ and the numbers of items $(i=1,2)$, the value of parameters adopted in this study are $A_{p i}=90$, $A_{s i}=40, A_{r i}=80, h_{p i}=0.8, h_{s i}=0.5, h_{r i}=1, \theta_{1 i}=0.3, \theta_{2 i}=0.2, \theta_{3 i}=0.5, c_{p i}=6, c_{s i j}=2, c_{r i}=10, P_{i}=800, d_{i}$ $=200, \mathrm{k}=3, \mathrm{l}=2$ and $\mathrm{m}=2$.

The computational results are shown in Table 1 (For $n=1)$ and Table 2 (For $n=2)$. The raw material, producer and retailer's costs are presented in Table 3.

The major conclusions and the special condition are drawn from numerical are as follow;

- When producer's different units produce the two type of items i.e. for $n=2$, the optimal values of The Total Cost is $\$ 26380$ and other optimal values of $l, T_{1}^{*}, T_{2}^{*}, T_{3}^{*} T, Q_{s}^{*}, Q_{p}^{*}, Q_{r}^{*}, T C S^{*}, T C P^{*}$ and $T C R^{*}$ are 2, 0.039, 0.013, 0.026, 0.052, 125 units, 124 units, 31 units, \$19972, \$17874, and \$91117.

- Since TC is the function of T, an optimization technique as shown on section 4(solution procedure) is used to find the optimal solution. A graphical representation and numerical analysis are also presented to show the convexity of the TC. Based on above analysis and graphical representation 
of Fig. 3(a) and Fig. 3(b), one can say that TC is a convex function. When $l^{*}=2$, the sufficient condition is $T C^{! !}=2.29654 \times 10^{6}$

Table 1

The numerical results for illustrated example when $\mathrm{n}=1$

\begin{tabular}{llllllllllll}
\hline $\boldsymbol{l}$ & $T_{1}$ & $T_{2}$ & $T_{3}$ & $T$ & $Q_{s}$ & $Q_{p}$ & $Q_{r}$ & TCS & TCP & TCR & TC \\
\hline $\mathbf{1}$ & 0.068 & 0.022 & 0.091 & 0.091 & 109.9 & 108.8 & 56.0 & 5751 & 4581 & 21212 & 6868 \\
$\mathbf{2}$ & 0.048 & 0.016 & 0.032 & 0.063 & 77.3 & 76.8 & 19.3 & 5743 & 5010 & 4666 & 7845 \\
$\mathbf{3}$ & 0.043 & 0.014 & 0.018 & 0.054 & 69.2 & 68.8 & 10.8 & 6180 & 5113 & 19518 & 8516 \\
\hline
\end{tabular}

Table 2

The numerical results for illustrated example when $\mathrm{n}=2$

\begin{tabular}{llllllllllll}
\hline $\boldsymbol{l}$ & $T_{1}$ & $T_{2}$ & $T_{3}$ & $T$ & $Q_{s}$ & $Q_{p}$ & $Q_{r}$ & TCS & TCP & TCR & $T C$ \\
\hline $\mathbf{1}$ & 0.043 & 0.014 & 0.058 & 0.058 & 138 & 137 & 70 & 20157 & 17351 & 81739 & 29793 \\
$\mathbf{2}$ & 0.039 & 0.013 & 0.026 & 0.052 & 125 & 124 & 31 & 19972 & 17874 & 91117 & 26380 \\
$\mathbf{3}$ & 0.034 & 0.011 & 0.015 & 0.045 & 109 & 108 & 18 & 23078 & 18517 & 85003 & 27334 \\
\hline
\end{tabular}

- This whole discussion is made for $n=2$ i.e. the producer produces and supplies to the all retailers the two types of items (Table 2 and Table 3 ).

- When 1 increases $T_{1}, T_{2}$, and $T_{3}$ will decrease. The reason is multiple deliveries will avoid the excess inventory.

- If $l>3$, all costs consistently increase, i.e. $l=2$ is the optimal value.

- When the deterioration is not considered (i.e. $\left.\theta_{1}, \theta_{2}, \theta_{3}=0\right), \mathrm{l}=2$ and $\mathrm{TC}^{*}$ is 16111.7 . The holding cost and item cost will increase.

Table 3

The Raw material, Producer and Retailer's cost (For n=2)

\begin{tabular}{llll}
\hline Cost Item & $l=1$ & $l=2$ & $L=3$ \\
\hline$S_{p}$ & 180 & 180 & 180 \\
$H C_{p}$ & 0.776 & 0.646 & 0.484 \\
$D C_{p}$ & 1296 & 1497 & 1305 \\
\hline TCP & 17351 & 17874 & 18517 \\
$O C_{s}$ & 80 & 80 & 80 \\
$H C_{s}$ & 5.95 & 4.89 & 3.715 \\
$I T_{s}$ & 874 & 1010 & 879 \\
TCS & 20157 & 19972 & 23078 \\
$O C_{r}$ & 160 & 160 & 160 \\
$H C_{r}$ & 12.25 & 2.44 & 0.0812 \\
$I T_{r}$ & 3283 & 1886 & 1084 \\
TCR & 81739 & 91117 & 85003 \\
\hline TC & 29790 & 26380 & 27334 \\
\hline
\end{tabular}




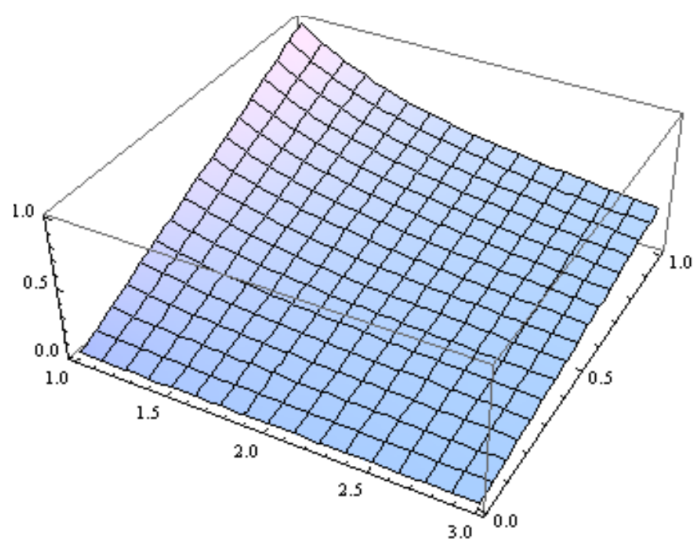

Fig. 3(a)

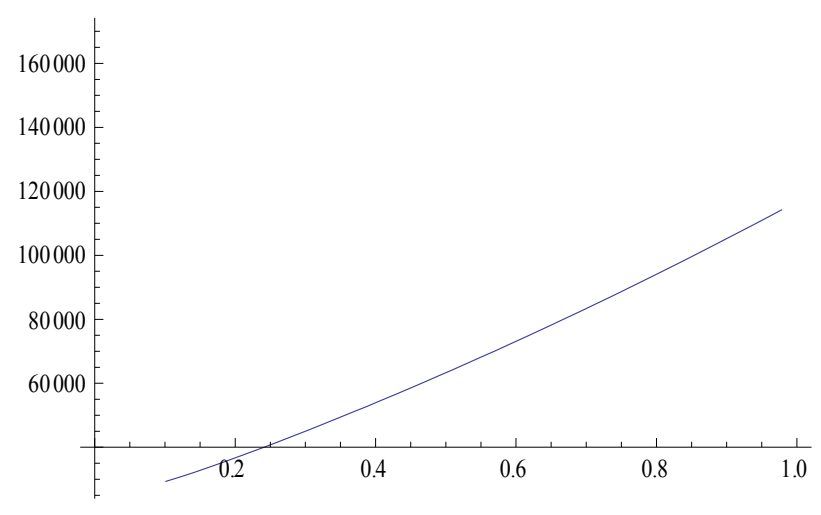

Fig. 3(b)

- Fig. 3 (a) shows the variation of total system cost with respect to the no. of delivery ( 1 from 1 to 3 ) and cycle time (T from 0 to 1 ).

- Fig. 3 (b) shows the variation of total system cost with respect to cycle time $(T)$.

\section{Conclusions}

This paper has presented a coordination policy among the suppliers, the producer and the retailers. To best of our knowledge, this is the first work in this field. The paper is considered the problem in which multiple suppliers, single producer and multiple retailers are involved and producer produces various kinds of multi-items and supplies all types of items to the retailers. A mathematical model has been developed with numerical examples provided. This model achieves coordination amongst the members in a supply chain assuming common cycle time for all non-identical retailers. This facilitates the consolidation of orders by producer and subsequently by the suppliers. Consolidation of orders in a supply chain results in reducing the order processing costs of chain members, while fulfilling the annual demand. Separate rate for deterioration have been taken for suppliers, producer and retailers, which is completely practical (raw material, finished goods in factory and finished goods in shop always deteriorate with different rate of deterioration).

Multiple deliveries are the most important policies to reduce inventory. The integrated decision also results in a lower optimal joint cost when compared with an independent decision by the producer or the retailers. To make it acceptable to all parties, the integrated policy should offer some kind of profit sharing. The study is particularly useful for the inventory systems where producer, their suppliers and their retailers form a strategic alliance with a mutually benefit objective. Future research can be performed for multi-producer-retailer chain.

\section{Acknowledgement}

The first author is very much thankful to the council of scientific and industrial research (CSIR) New Delhi, India for the financial assistance in the form of Junior Research Fellowship (JRF).

\section{References}

Aliabadi, D. E., Kaazemi, A. \& Pourghannad, B. (2013). A two-level GA to solve an integrated multiitem supplier selection model. Applied Mathematics and Computation, 219(14), 7600-7615.

Clark, A. J., \& Scarf, H. (1960). Optimal policies for a multi echelon inventory problem. Management Science, 6, 475-490. 
Chui, Y. S., Huang, C. C., Wu, M. F. \& Chang, H. H. (2013). Joint determination of rotation cycle time and number of shipments for a multi-item EPQ model with random defective rate. Economic Modelling, 35, 112-117.

Goyal, S. K., \& Gupta, Y.P. (1989). Integrated inventory models: The buyer-vendor coordination. European Journal of Operational Research, 41(3), 261-269.

Goyal, S. K., \& Gunasekaran, A. (1995). An integrated production-inventory-marketing model for deteriorating items. Computers and Industrial Engineering, 28, 755-762.

Ganeshan, R. (1999). Managing supply chain inventories: a multiple retailer, one warehouse, multiple supplier models. International Journal of Production Economics, 59, 341-354.

Goyal, S. K. (2000). On improving the single-vendor single-buyer integrated production inventory model with a generalized policy. European Journal of Operational Research, 125 (2), 429-430.

Hill, R. M. (1997). The single-vendor single-buyer integrated production-inventory model with a generalized policy. European Journal of Operational Research, 97 (3), 493-499.

Hanbali, A. A. \& Heijden, M. V. (2013). Interval availability analysis of a two-echelon, multi-item system. European Journal of Operational Research, 228 (1), 494-503.

Jaber, M. Y., Osman, I. H., \& Guiffrida, A.L. (2006). Coordinating a three-level supply chain with price discounts, price dependent demand and profit sharing. International Journal of Integrated Supply Management, 2 (1-2), 28-48.

Jaber, M. Y., \& Goyal, S. K. (2008). Coordinating a three-level supply chain with multiple suppliers, a vendor and multiple buyers. International Journal of Production Economics, 116, 95-103.

Jain, R. \& Singh, S. R. (2011). Inflation implication on an inventory with expiration date, capital constraint and uncertain lead time in a multi-echelon supply chain. International Journal of Procurement Management, 4 (4), 419-432.

Singh, S. R., Kumar, N. \& Kumari, R. (2012). Three echelon supply chain inventory model for deteriorating items with storage facility and lead time under inflation. International Journal of Services and Operations Management, 13 (1), 98-118.

Lenard, J. D. \& Roy, B. (1995). Multi-item inventory control: A multi criteria view, European Journal of Operational Research, 87, 685-692.

Ben-Daya, M. \& Raouf, A. (1993). On the constrained multi-item single-period inventory problem. International journal of Production Management, 13, 104-112.

Munson, C. L. \& Rosenblatt, M. J. (2001). Coordinating a three-level supply chain with quantity discounts. IIE Transactions, 33 (5), 371-384.

Pal, B., Sana, S. S. \& Chaudhari, K. S. (2012). A three layer multi-item production-inventory model for multiple suppliers and retailers. Economic Modelling, 29(6), 2704-2710.

Rosenblatt, M. J. (1981). Multi-item inventory system with budgetary constraint: A comparison between the Lagrangian and the fixed cycle approach. International Journal of Production Research, 19(4), 331-339.

Sadjadi, S. J., Yazdian, S. A. \& Shahanaghi, K. (2012). Optimal pricing, lot-sizing and marketing planning in a capacitated and imperfect production system. Computers \& Industrial Engineering, 62(1), 349-358.

Thomas, D. J. \& Grifin, P. J. (1996). Coordinated supply chain management. European Journal of Operational Research, 94, 1-15.

Viswanathan, S. \& Wang, Q. (2003). Discount pricing decisions in distribution channels with pricesensitive demand. European Journal of Operational Research, 149 (3), 571-587.

Tsao, Y. C. \& Sheen, G. J. (2012). A multi-item supply chain with credit periods and weight freight cost discounts. International Journal of Production Economics, 135(1), 106-115. 